\title{
PELATIHAN PENDIDIKAN KARAKTER BAGI GURU-GURU MELALUI METODE CODING BERBASIS STEAM
}

\author{
Meiske Yunithree Suparman ${ }^{1}$, Ninawati ${ }^{2}$, dan Kurnia Setiawan ${ }^{3}$ \\ ${ }^{1}$ Fakultas Psikologi, Universitas Tarumanagara \\ Email: meiskey@fpsi.untar.ac.id \\ ${ }^{2}$ Fakultas Psikologi, Universitas Tarumanagara \\ Email: ninawati@fpsi.untar.ac.id \\ ${ }^{3}$ Fakultas Seni Rupa dan Desain, Universitas Tarumanagara \\ Email: kurnias@fsrd.untar.ac.id
}

\begin{abstract}
Indonesia is known as a nation of culture and values. However, the development of the times has led Indonesians to a shift in native cultural values that were once highly valued. Thus, learning about the character is necessary in order to restore the values that become the nation's identity. However, existing theoretical character learning bores students and makes students feel less interested in learning about character. Therefore, practical learning methods need to be interesting, one of which is STEAM-based coding. We started with the teachers' training. Training is given to early childhood education teachers, kindergarten, and elementary schools of the 15 selected schools. Training is carried out from December 2020 to June 2021. This training is conducted four times in harmony with four subjects adopted by Yayasan Amal Bhakti Ibu Indonesia (YABII); there are peace, harmony between religiosity, ethnic groups, and social strata, helping one another, and love of the country. Training includes exposure theory combined with the coding game by Rumah Edukasi, and assignment for participants. These activities gave participants new insights into a new way to develop the character building of Indonesian children.
\end{abstract}

Keywords: teachers training, character building, STEAM-based coding

\begin{abstract}
ABSTRAK
Bangsa Indonesia dikenal sebagai bangsa yang berbudaya dan memiliki nilai-nilai luhur. Namun, perkembangan zaman telah membawa masyarakat Indonesia kepada pergeseran nilai-nilai budaya asli yang dulu sangat dijunjung tinggi. Dengan demikian, perlu adanya pembelajaran karakter untuk mengembalikan nilai-nilai yang menjadi identitas bangsa. Pembelajaran karakter dengan metode teoritis membuat siswa bosan dan kurang berminat untuk belajar. Oleh karena itu, perlu metode praktis yang menarik minat belajar siswa, salah satunya adalah metode coding berbasis STEAM. Pelatihan diberikan kepada guru-guru PAUD, TK, hingga SD dari 15 sekolah yang terpilih secara daring. Pelatihan dilaksanakan pada periode Desember 2020 hingga Juni 2021. Pelatihan ini dilaksanakan sebanyak 4 kali sesuai dengan 4 tema yang diusung oleh YABII yakni perdamaian, kerukunan antar umat beragama, suku, dan lapisan sosial, tolong menolong, serta cinta tanah air. Pelatihan meliputi pemaparan teori yang digabungkan dengan permainan coding oleh Rumah Edukasi, dan penugasan bagi para peserta. Kegiatan ini memberikan wawasan baru kepada para peserta mengenai cara baru mengembangkan pendidikan karakter anak bangsa.
\end{abstract}

Kata kunci: pelatihan guru, pembentukan karakter, coding berbasis STEAM

\section{PENDAHULUAN}

Bangsa Indonesia merupakan bangsa yang terkenal karena keberagamannya baik keberagaman suku, agama, budaya, serta bahasa dan sejarah lokal. Perbedaan dan keberagaman ini harus dapat dijadikan modal sosial yang berguna bagi kemajuan dan kesejahteraan bangsa (Yayasan Amal Bhakti Ibu Indonesia, 2015). Pada dasarnya, masyarakat Indonesia dikenal sebagai bangsa yang berbudaya dan memiliki nilai-nilai luhur. Nilai-nilai luhur ini diturunkan secara turun temurun dari satu generasi ke generasi melalui berbagai sarana dan kesempatan. Namun, kondisi masyarakat yang ditandai dengan banyaknya kejahatan sebagaimana diuraikan di atas, menunjukkan pergeseran pada nilai-nilai luhur yang menjadi ciri khas bangsa Indonesia. Nilainilai budaya lokal, yang disebut kearifan lokal, menjadi semakin terlupakan (Husna dan Fahmi, 2019). Untuk mengembalikan nilai-nilai ini ke dalam tatanan masyarakat Indonesia yang 
berkepribadian luhur, setiap orang perlu memaknai ulang dan menginternalisasi nilai-nilai ini dalam kehidupan sehari-hari.

Usaha membangun kesejahteraan bangsa merupakan upaya berkelanjutan, khususnya pembangunan manusia Indonesia yang harus dimulai sejak usia dini, bahkan sejak janin dalam kandungan. Pembangunan manusia mempunyai 2 aspek yang saling terkait, yaitu pembangunan fisik dan pembangunan mental. Pembangunan mental juga mempunyai 2 aspek yang tak terpisahkan, yaitu pembangunan kecerdasan dan pembangunan karakter atau kepribadiannya (Madiarsa, 2015). Pembangunan karakter manusia yang dimulai pada usia dini sangat efektif karena pendidikan pada usia itu paling membekas dalam kehidupan seseorang. Di sinilah letak arti pendidikan karakter sejak dini bagi anak Indonesia yang digeluti oleh Yayasan Amal Bhakti Ibu Indonesia.

Sejak tahun 2002 Yayasan Amal Bhakti Ibu Indonesia (YABII) mengembangkan program pendidikan karakter atau pendidikan tentang perdamaian dan nilai-nilai hidup positif lainnya bagi anak-anak usia balita, prasekolah, sekolah dasar dan sekolah menengah pertama. Program tersebut dinamakan program Anak Indonesia Membangun Budaya Damai (AIMDAMAI) yang diresmikan oleh Presiden RI pada tanggal 31 Mei 2002 di Jakarta. Program tersebut mengangkat 4 tema, yaitu perdamaian, kerukunan antar umat beragama, suku dan status sosial ekonomi, tolong menolong, dan cinta tanah air (Yayasan Amal Bhakti Ibu Indonesia, 2015). Perdamaian dalam arti luas memberikan penekanan pada hidup yang tidak penuh konflik, sedangkan kerukunan antar berbagai latar kehidupan menunjukkan walaupun banyak perbedaan, bangsa Indonesia merupakan bangsa yang satu. Tolong menolong merupakan karakter yang penting untuk dikembangkan. Baumeister dan Bushman (2014) serta Myers (2015) mendefinisikan tindakan tolong menolong sebagai tindakan melakukan sesuatu hal baik untuk orang lain atau masyarakat. Cinta tanah air mutlak diperlukan untuk mempertahankan rasa kebersamaan sebagai bangsa Indonesia.

AIMDAMAI merupakan program yang bersifat multisektoral karena terminologi digunakan dalam arti luas, bukan saja dalam arti pendidikan formal di sekolah, tetapi termasuk juga pengasuhan anak sejak usia dini dalam keluarga, pengasuhan anak di panti-panti asuhan , pendampingan anak-anak jalanan dan anak-anak yang trauma pasca kerusuhan atau pasca bencana, dan sebagainya. Oleh karena itu, dalam pelaksanaan program AIMDAMAI, YABII bekerja sama dengan berbagai Kementerian, di antaranya yaitu Kementerian Koordinator Kesejahteraan Rakyat, Kementerian Pendididkan dan Kebudayaan, Kementerian Agama, Kementerian Sosial, Kementerian Dalam Negeri, serta Kementerian Pemberdayaan Perempuan dan Perlindungan Anak.

YABII telah melaksanakan kegiatan Anak Indonesia Cinta Damai (AICINDA) sebagai bagian dari AIMDAMAI dalam rangka memperingati hari-hari bersejarah seperti Kebangkitan Nasional, Hari Anak Nasional, HUT Kemerdekaan, Sumpah Pemuda dan Hari Ibu. Kegiatan AICINDA adalah kegiatan bersama, oleh dan untuk anak-anak usia 4-13 tahun dari berbagai latar belakang agama, etnis dan suku, serta lapisan sosial.

AICINDA mencakup 3 bentuk aktivitas, yaitu:

1. Menyanyi dan menari oleh anak-anak usia 4-6 tahun,

2. Menggambar oleh anak-anak usia 7-9 tahun,

3. Diskusi oleh anak-anak usia 10-13 tahun.

Ketiga aktivitas tersebut dipandu oleh empat tema yang menjadi tujuan program AIMDAMAI yang difasilitasi oleh para fasilitator yang terlebih dahulu telah mendapat pelatihan khusus dari YABII. Oleh karena itu, selain kegiatan anak-anak yang berlangsung hanya setengah hari, kegiatan AICINDA juga mencakup pelatihan fasilitator selama 2 hingga 3 hari. Pada perkembangan selanjutnya, kegiatan-kegiatan diarahkan juga kepada kelompok sasaran pendidikan yang lebih tinggi, yaitu kepada siswa SMP maupun SMA. Guru-guru yang telah 
dilatih akan meneruskan ilmu yang diperolehnya kepada anak didiknya, sehingga rantai ilmu ini tidak terputus.

Berdasarkan uraian di atas, perlunya sebuah terobosan baru untuk pembelajaran karakter yang disesuaikan dengan keadaan sekarang untuk mempersiapkan generasi emas Indonesia. Pada tahun 2020 YABII Pusat merencanakan melaksanakan Program Pembelajaran Coding AIMDAMAI bagi institusi pendidikan kurang mampu, baik anak panti maupun anak non panti serta anak-anak jalanan di Jabodetabek yang mewakili 6 agama. Program ini akan menjadi model untuk dapat direplikasi di daerah-daerah lain dan di Jabodetabek sendiri.

Universitas Tarumanagara selama ini telah menjadi mitra yang kompeten bagi Yayasan Amal Bhakti Ibu Indonesia (YABII). Pendidikan karakter yang dicanangkan sejak hampir 20 tahun lalu secara konsisten telah melibatkan beberapa dosen dari Universitas Tarumanagara, khususnya Fakultas Psikologi. Dengan program dan metode baru ini, diharapkan semakin banyak dosen dari berbagai Fakultas di Universitas Tarumanagara yang dapat dilibatkan sehingga kontribusi Universitas Tarumanagara dalam memajukan pendidikan dan meningkatkan kualitas anak bangsa akan semakin nyata.

\section{TUJUAN KEGIATAN}

Tujuan kegiatan ini adalah untuk meningkatkan metode baru dalam pembelajaran karakter adalah melalui metode coding berbasis STEAM. Hal ini merupakan suatu terobosan baru dan diakui sebagai metode kreatif pertama yang menggabungkan antara pembelajaran karakter dengan metode coding berbasis STEAM.

YABII telah memiliki beberapa modul yang masih sangat terbuka untuk dikembangkan di kemudian hari yakni modul perdamaian, kerukunan antar umat beragama, suku, dan lapisan masyarakat, tolong menolong, dan modul cinta tanah air. Modul perdamaian bertujuan agar anak-anak mampu merasakan hidup dalam ketenangan dan kedamaian, bertanggung jawab, serta dapat menyelesaikan konflik dengan damai. Modul kerukunan antar umat beragama, suku, dan lapisan masyarakat bertujuan agar anak-anak mampu memahami makna kerukunan di atas berbagai perbedaan yang ada dan mampu menerima dan menghargai perbedaan yang ada. Modul tolong menolong bertujuan untuk melatih anak mampu secara mandiri memenuhi kebutuhannya sendiri, menolong orang lain yang membutuhkan, dan membangun empati. Modul cinta tanah air membuat anak lebih mencintai Indonesia dengan penuh tanggung jawab sebagai anak bangsa.

Melalui modul dan metode pembelajaran karakter yang baru ini, pihak-pihak yang berkepentingan akan mendapatkan berbagai solusi di antaranya:

1. Menggugah kepedulian semua pihak terhadap arti penting pembangunan budaya damai melalui pendidikan sejak usia dini, guna mewujudkan Indonesia yang kuat dan bersatu dalam kebhinnekaan, maju, sejahtera, adil, serta bermartabat dan dihormati dalam pergaulan antar bangsa-bangsa di dunia,

2. Mengajak semua pihak untuk menghormati dan melaksanakan hak-hak anak serta bekerja keras bersama-sama membangun kehidupan yang lebih baik bagi anak-anak Indonesia,

3. Belajar coding tanpa komputer yang dapat mengembangkan keterampilan komputasional, analisa, matematika, kreativitas, dan memecahkan masalah,

4. Belajar merakit robot dan konstruksi berbasis STEAM (Science, Technology, Engineering, Art, Mathematics).

Berdasarkan tujuan program pembelajaran karakter AIMDAMAI, diharapkan terlaksananya pembelajaran coding AIMDAMAI antara guru/pendidik/pendamping dari institusi pendidikan kurang mampu, panti asuhan, sekolah alternatif dan anak jalanan bersama anak-anak asuhan/didiknya yang dapat dijadikan salah satu modal pelaksanaan program AIMDAMAI. 
Pembelajaran akan diselenggarakan dalam bentuk workshop kepada guru-guru PAUD, TK, hingga SD pada gelombang pertama ini. Workshop akan dilakukan 4 kali sesuai dengan keempat tema yang diusung oleh Yayasan Amal Bhakti Ibu Indonesia. Bagi sekolah-sekolah yang kurang mampu akan menerima subsidi peralatan coding, sehingga dapat menerapkan langsung prinsipprinsip STEAM dan mengaitkannya dengan pendidikan karakter. Workshop dilaksanakan secara daring. Luaran lain yang dihasilkan dari kegiatan ini adalah prosiding pada temu ilmiah.

\section{METODE PELAKSANAAN PKM}

\section{Langkah-Langkah/Tahapan Pelaksanaan}

Secara garis besar, langkah-langkah dari pelaksanaan kegiatan pengabdian kepada masyarakat ini adalah diawali dengan LPPM menginformasikan tentang pengajuan proposal dari sumber dana internal LPPM, dan tim dosen pengabdian kepada masyarakat mulai membuat proposal. Tim kemudian menghubungi pihak mitra, yaitu Yayasan Amal Bhakti Ibu Indonesia (YABII) yang disambut dengan respon positif. Setelah berdiskusi, diputuskan bahwa tim akan terlibat dalam kegiatan pembelajaran karakter melalui metode coding berbasis STEAM. Program ini telah diluncurkan pada bulan Desember 2020, dengan didukung oleh Kementerian Pedidikan dan Kebudayaan RI.

\section{Partisipasi Mitra dalam Kegiatan PKM}

YABII akan membantu membentuk tim pelatih yang melibatkan pihak YABII dan Universitas Tarumanagara. Selain itu, YABII juga akan memberikan subsidi peralatan coding bagi sekolahsekolah yang kurang mampu menyediakan peralatan coding untuk mengikuti pelatihan ini. Pihak YABII juga menyeleksi sekolah-sekolah tersebut dan hanya membantu sekolah-sekolah yang memiliki komitmen untuk mengikuti pelatihan hingga tuntas dan mau mengembangkan pembelajaran ini di sekolah masing-masing. YABII juga membantu menyedikan tim monitoring untuk memonitor pelaksanaan pembelajaran karakter ini di sekolah masing-masing hingga bulan Juni 2021. Tim monitoring ini juga akan melibatkan tim dosen dari Universitas Tarumanagara.

\section{Kepakaran dan Pembagian Tugas Tim}

Dalam setiap kegiatan pengabdian masyarakat yang dilakukan oleh dosen dibutuhkan keahlian yang khusus sesuai dengan target dan luaran yang hendak dicapai. Universitas Tarumanagara telah memiliki 8 Fakultas yang mampu mengakomodir kebutuhan keahlian dalam pengabdian di masyarakat. Ke delapan fakultas tersebut adalah: Fakultas Ekonomi, Fakultas Hukum, Fakultas Teknik, Fakultas Kedokteran, Fakultas Seni Rupa dan Desain, Fakultas Psikologi, Fakultas Teknik Informasi, dan Fakultas Ilmu Komunikasi.

Sumber daya manusia yang terlibat dalam kegiatan ini adalah dosen yang memiliki kepakaran untuk menyelesaikan persoalan mitra. Berikut disajikan dalam tabel 1 kepakaran masing-masing dosen, untuk kegiatan kali ini dosen yang terlibat adalah dosen Fakultas Psikologi dan Fakultas Seni Rupa dan Desain, serta mahasiswa Fakultas Psikologi yang akan membantu.

\section{HASIL DAN PEMBAHASAN}

Pada hari yang telah ditentukan, hadir narasumber dari Universitas Tarumanagara, serta mitra PKM, yaitu YABII. Di samping itu, YABII juga bermitra dengan Universitas YARSI. Rektor dari Universitas YARSI, yaitu Prof. Dr. dr. Fasli Djalal, Ph. D. berkenan hadir juga dan memberikan komentar dan masukan, serta penutup pada acara.

Melalui serangkaian rapat dengan pihak mitra, kegiatan dirancang dengan rencana awal untuk mengadakan seleksi untuk memberikan bantuan kepada sekolah-sekolah yang memenuhi kriteria tertentu, yakni merupakan sekolah yang tergolong memiliki siswa dengan status ekonomi 
rendah, bersedia mengikuti seluruh acara hingga selesai, mengerjakan tugas dengan lengkap dan baik, serta lolos wawancara. Melalui seleksi ketat, terpilih 15 sekolah yang memperoleh dukungan peralatan tersebut. Sekolah-sekolah yang belum memperoleh kesempatan ini, tetap dapat mengikuti setiap sesi melalui platform youtube.

Para narasumber mengisi setiap sesi dengan materi tentang karakter, sesuai dengan 4 tema karakter yang diusung YABII, yaitu perdamaian, kerukunan antar umat beragama, suku, dan lapisan sosial, tolong menolong, serta cinta tanah air. Lalu materi digabungkan dengan permainan coding yang diajarkan oleh Rumah Edukasi. Setelah itu diberikan penugasan bagi para peserta, sehingga peserta tidak hanya mendengarkan teori dan mencoba saat sesi praktik, namun juga dapat mengerjakan tugas yang diberikan.

Berdasarkan masukan dari para peserta, kegiatan ini sangat bermanfaat karena memberikan wawasan baru mengenai cara baru mengembangkan pendidikan karakter anak bangsa. Metode ini merupakan metode yang pertama di Indonesia, sehingga dapat dikatakan bahwa ini merupakan inovasi dalam bidang pendidikan.

\section{KESIMPULAN DAN SARAN}

\section{Kesimpulan}

Kegiatan ini merupakan suatu inovasi baru dalam bidang pendidikan. Menggabungkan tentang pendidikan karakter dan STEAM bukan merupakan hal yang mudah untuk dilakukan, terutama untuk mereka yang belum fasih menggunakan prinsip STEAM. Oleh karena itu, perlu dilakukan beberapa kali pelatihan dalam bentuk penyampaian materi, praktik, dan penugasan. Terbukti ketika semua berjalan dengan baik, inovasi ini memberikan banyak manfaat bagi para peserta.

\section{Saran}

Kegiatan ini perlu dilakukan dengan target peserta lebih luas, dan jenjang pendidikan yang berbeda pula. Kegiatan yang dilaksanakan kali ini diaplikasikan pada tingkat PAUD, TK dan SD. Peneliti menyarankan kedepannya kegiatan ini dapat diterapkan pada jenjang pendidikan yang lebih tinggi, termasuk perguruan tinggi.

Pihak mitra yang terlibat juga memiliki peran yang sangat besar sesuai dengan kesepakatan masing-masing. Pihak mitra ini perlu dipertahankan dan dengan sinergi yang baik sehingga tujuan akan tercapai.

\section{Ucapan Terima Kasih (Acknowledgement)}

Ucapan terima kasih diberikan kepada Kementerian Pendidikan dan Kebudayaan RI, Yayasan Amal Bhakti Ibu Indonesia (YABII), serta LPPM Universitas Tarumanagara.

\section{REFERENSI}

Baumeister, R. F. \& Bushman, B. J. (2014). Social psychology and human nature. $3^{\text {rd }}$ Ed. Canada: Wadsworth, Cengage Learning.

Husna, W. \& Fahmi, R. (2019). Hubungan kebersyukuran dengan perilaku prososial pada mahasiswa. Jurnal Psikologi Islam Al-Qalb. 10(2), 179-188.

Madiarsa, I. M. (2015). Lokal genius dalam kajian manajemen. Prosiding Seminar: Lokal genius dalam perspektif kebijakan publik, hukum, manajemen, pertanian, dan pendidikan. ISBN 978-979-17627-1-4.

Myers, D.G. (2010). Social psychology (10 ${ }^{\text {th }}$ edition). Boston: McGraw-Hill.

Yayasan Amal Bhakti Ibu Indonesia (2015). Pendidikan Karakter: Anak Indonesia Membangun Budaya Damai. Jakarta: YABII 
Seminar Nasional Hasil Penelitian dan Pengabdian Kepada Masyarakat 2021

Pengembangan Ekonomi Bangsa Melalui Inovasi Digital Hasil Penelitian dan

Pengabdian Kepada Masyarakat

Jakarta, 21 Oktober 2021

(lampiran kosong) 